\title{
Relations between passage rates of rumen fluid and particulate matter and foam production in rumen contents of cattle fed on different diets ad lib.
}

\author{
BY E. K. OKINE, G. W. MATHISON* AND R. T. HARDIN \\ Department of Animal Science, University of Alberta, Edmonton, \\ Alberta, T6G 2P5, Canada
}

(Received 26 November 1987 - Accepted 19 September 1988)

\begin{abstract}
1. A group of six cattle, three of which had a non-bloating history (group A) and had been ruminally cannulated for the previous 2 years, and three with a history of being bloat-prone (group B) and which had been ruminally cannulated only 3 months before the study, were fed ad lib. on chopped lucerne (Medicago sativa) hay, lucerne pellets, or a $100 \mathrm{~g}$ chopped hay and $900 \mathrm{~g}$ rolled barley grain $/ \mathrm{kg}$ diet over three periods of $30 \mathrm{~d}$ each. Flow of rumen digesta, by reference to CoEDTA and chromium-mordanted fibres, and foam production from samples of rumen contents were measured.

2. Samples of rumen contents $(50 \mathrm{ml})$ from group A produced foam heights of 150 and $60 \mathrm{~mm}, 2$ and $4 \mathrm{~h}$ after feeding respectively, compared with 240 and $150 \mathrm{~mm}$ for group B $(P<0.05)$.

3. The fractional passage rate of the $1-2 \mathrm{~mm}$ particles mordanted with $\mathrm{Cr}$ did not differ $(P>0.05)$ between groups.

4. The fractional outflow rates (FOR) for CoEDTA $0-2 \mathrm{~h}$ and $2-7 \mathrm{~h}$ after feed was offered were $0 \cdot 205$ and $0.160 / \mathrm{h}$ for group A and 0.093 and $0.086 / \mathrm{h}$ for group B respectively $(P<0.05)$.

5. Rumen-fluid FOR $0-2 \mathrm{~h}$ and $2-7 \mathrm{~h}$ after provision of feed were significantly $(P<0.05)$ inversely correlated ( $r-0.74$ and -0.85 respectively) with the amount of foam produced from rumen contents at these times.
\end{abstract}

Feedlot and legume bloat have both been postulated to be caused by complex interrelations between plant, animal, environmental, and microbial factors (Mendel \& Boda, 1961; Howarth et al. 1986). Among the numerous animal factors, bloat-prone cattle in comparison with non-bloating cattle have been reported to secrete less saliva during feeding and resting (Mendel \& Boda, 1961), have a higher particulate-matter content in the rumen, as estimated by chlorophyll content (Majak et al. 1983, 1986 a; Howarth et al. 1986), and also have larger rumen volumes (Cockrem et al. 1983).

Indeed the evidence of a higher chlorophyll concentration in digesta contents, in spite of a larger volume of rumen digesta in bloat-prone cattle compared with non-bloating cattle, is consistent with a slower overall rate of passage of liquid markers from the rumen of the susceptible cattle (Majak et al. 1986 b). However, differences in overall rate of passage may be inadequate to explain differences between bloat-susceptible and non-susceptible animals. Although both types of cattle show increases in rumen particulate matter, as indicated by chlorophyll concentration $2 \mathrm{~h}$ after feeding, chlorophyll concentration in bloat-prone cattle continues to increase until $4 \mathrm{~h}$ after feeding, while the concentration remains approximately the same as at $2 \mathrm{~h}$ in non-bloating cattle (Majak et al. 1983). This would indicate differential passage rates from the rumen for the bloat-types of cattle at different times after feeding or differential rates of digestion.

The present study was designed to obtain information on the relations between particulate-matter (rumen-particle) and rumen-fluid passage rates (PPR and FPR respectively) and foam production between two different groups of cattle in situations reflecting normal ingestive behaviour. It was also designed to examine the effects of changes

* For reprints. 
in marker-dilution curves before, during, and after feeding on the amounts of foam produced from rumen contents of cattle given various feeds.

\section{MATERIALS AND METHODS}

Three cattle $(539 \mathrm{~kg})$ of Hereford breeding with a history of not being susceptible to bloat (group A), and which had been cannulated 2 years previously, and three cattle $(386 \mathrm{~kg})$ also of Hereford breeding with a history of being bloat-susceptible (group B) and which had been ruminally cannulated for 3 months were used in this study. Each of the three group A cattle were randomly paired with the group B cattle, forming three pairs of animals. These pairs were used in a split-plot experiment with whole plots being a $3 \times 3$ Latin square with three periods, three diets and three animal pairs. The split-plots of the experiment were the two animal groups. Each period consisted of $30 \mathrm{~d}$ with one animal from each group receiving one of the three different diets.

The three diets used in the experiment were (1) lucerne (Medicago sativa) pellets (pellets) which contained $(\mathrm{g} / \mathrm{kg}) 30 \cdot 2$ nitrogen and 450 cell-wall contents (CWC) on a dry matter (DM) basis, (2) chopped lucerne hay (hay) which contained $22 \cdot 1 \mathrm{~N}$ and $505 \mathrm{CWC}$, and (3) $900 \mathrm{~g}$ rolled barley grain $(20 \mathrm{~N}$ and $172 \mathrm{CWC})$ and $100 \mathrm{~g}$ chopped hay fed as a mixture (concentrate).

\section{Voluntary feed intake measurements}

The diets were offered ad lib. twice daily at 09.00 hours and at 16.00 hours. The first allocation of feed was about $75 \%$ of the total with the remainder being offered at 16.00 hours. Trace-mineralized salt blocks and water were available ad lib. Voluntary feed consumption was measured over $12 \mathrm{~d}$ by offering the diets in sufficient amounts to allow for $10 \%$ rejection. Thereafter the feed was offered at the maximum eaten by day 12 for another $9 \mathrm{~d}$ before measurements commenced. On two separate occasions during each period measurements were recorded of the initial intake of individual cattle, after provision of fresh feed, until the cattle first left the feedbunk. In addition, the number of visitations made by the animals to feed were recorded and these were used to calculate the average meal size over an $8-12 \mathrm{~h}$ period.

\section{Foam measurements}

The foaming properties of rumen fluid from the various cattle were examined according to the procedure of Pressey et al. (1963). Briefly, $50 \mathrm{ml}$ fresh rumen fluid were poured into a glass cylinder (20 mm internal diameter and $500 \mathrm{~mm}$ in length) and carbon dioxide gas was bubbled through a bottom inlet at $2 \mathrm{kPa}$ for $2 \mathrm{~min}$, resulting in conversion of most of the fluid to foam. Foam height, measured as the height of foam at the interface of fluid and foam in the cylinder, was used as a measure of foam production. Foam instability was calculated as the difference between intial foam height and the foam height 5 min after cessation of gassing, expressed as a percentage of initial foam height.

\section{Passage rate studies}

FPR was determined using crystalline CoEDTA prepared according to the procedures of Uden et al. (1980). The particulate marker used in the present study for PPR was chromium-mordanted to fibre. The fibres for mordanting were prepared by soaking about $2 \mathrm{~kg}$ ground lucerne in water overnight. The material was then fractionated using a wetsieving procedure. The particles retained on the $1 \mathrm{~mm}$ screen after passing through the 2 $\mathrm{mm}$ were mordanted with $\mathrm{Cr}$ according to the method of Uden et al. (1980). The particles contained about $32 \mathrm{mg} \mathrm{Cr} / \mathrm{kg}$ after this procedure.

FPR studies were conducted on days 22 and 30 of each period, while PPR was determined from $\mathrm{Cr}$-mordanted particles introduced on day 22. The animals were dosed 
intraruminally with $5 \mathrm{~g}$ cobalt and $50 \mathrm{~g} \mathrm{Cr}$-mordanted particles simultaneously at 06.00 hours on the day of passage-rate studies, $3 \mathrm{~h}$ before feeding. In this procedure approximately half the rumen contents were removed, mixed with $\mathrm{Co}$ and $\mathrm{Cr}$-mordanted particles, and returned to the rumen.

Rumen-fluid samples for FPR were taken from various sections of the rumen at $0.5,1$, 2 and $3 \mathrm{~h}$ after dosing with markers $3-0 \mathrm{~h}$ before provision of feed, then every $0.5 \mathrm{~h}$ for the next $2 \mathrm{~h}$, and then hourly from 2 to $7 \mathrm{~h}$ after feed was offered. The contents were squeezed through four layers of cheesecloth, the filtrate was frozen and the solid particles returned to the rumen. Rumen samples for PPR determination were collected at 4, 24, 48 and 72 $\mathrm{h}$ after administration of the mordanted particles, subsampled and frozen for subsequent analysis.

\section{Laboratory procedures}

The DM of feed and rumen digesta were determined by oven drying at $80^{\circ}$ to constant weight. N concentration of feed was determined by standard procedures (Association of Official Analytical Chemists, 1975). CWC were determined by the method of Goering \& Van Soest (1970).

A subsample of the rumen fluid $(15 \mathrm{ml})$ was thawed, centrifuged $(39000 \mathrm{~g}$ for $10 \mathrm{~min})$ and the Co concentration determined after 1:5 dilution with $0 \cdot 1 \mathrm{M}$-hydrochloric acid by atomic absorption spectrophotometry (AAS) (model 4000; Perkin Elmer Corp., Norwalk, Conn. 06856, USA). Cr in rumen samples was determined according to the procedure of P. H. Robinson (personal communication) after oven drying $50 \mathrm{~g}$ of the rumen digesta for $3 \mathrm{~d}$ at $60^{\circ}$ and grinding the material to pass a $1 \mathrm{~mm}$ screen. The ground material $(500 \mathrm{mg})$ was soaked in $60 \mathrm{ml} 4 \mathrm{M}$-nitric acid for $4 \mathrm{~h}$ at room temperature and then for $12 \mathrm{~h}$ at $75^{\circ}$. The resultant solution was centrifuged $(39000 \mathrm{~g}$ for $5 \mathrm{~min}$ ) with the supernatant fraction being analysed for $\mathrm{Cr}$ using the AAS.

\section{Calculations and statistical analysis}

Movement of digesta from the rumen was calculated with reference to the CoEDTA and Cr-mordanted particle concentrations in the digesta. No correction was made for absorption of Co across the rumen wall, since no significant amounts of Co were detected in the urine.

The passage rate-constants for each marker were calculated as first-order rate-constants since first-order kinetic equations described more than $90 \%$ of the variance in the decline in concentration of each marker with time in thirty-three out of the thirty-six situations. Separate regressions were employed to determine the fractional outflow rates (FOR) during each sampling phase: $2 \cdot 5-0 \mathrm{~h}$ before feeding, $0-2 \mathrm{~h}$ after provision of feed and $2-7 \mathrm{~h}$ after feed was offered. Initial rumen volumes were calculated from the weights of CoEDTA given and the concentration of the marker at zero time as estimated by extrapolation using regression points before feeding (Stokes et al. 1985).

The rate-constants of both markers, foam heights, foam instabilities and rumen volumes were analysed as a split-plot with the whole plots being a $3 \times 3$ Latin square with three periods, three diets and three animal pairs. The two animal groups were the split-plot.

Rumen-fluid FOR $2 \cdot 5-0 \mathrm{~h}$ before feeding, and $0-2 \mathrm{~h}$ and $2-7 \mathrm{~h}$ after provision of feed were regressed against foam height and foam instabilities for these times. Differences between means were determined using analyses of variance procedures. When significant diet effects were detected, the diet means were compared using the Student-Newman-Keuls' range statistic (Steel \& Torrie, 1980). 


\section{RESULTS}

Voluntary feed intake measurements

DM intakes by cattle in group A for all the diets were greater $(P<0.05)$ than intakes by cattle in group $\mathbf{B}$, although the differences lacked significance when expressed relative to body-weight (Table 1). Also, although both mean initial intakes and average size of meal were greater $(P<0.05)$ for groups $\mathrm{A}$ than $\mathrm{B}$, there were no differences $(P>0.05)$ when both were expressed relative to body-weight (Table 1).

\section{Passage rate studies}

Multiple-component marker-concentration curves were obtained when the liquid marker was introduced $3 \mathrm{~h}$ before feeding (Fig. 1 as a representative example), with a sharp decline in Co concentration tending to occur during feeding.

Before feeding no differences were seen in FOR between animal groups or between diets. However, the FOR $0-2 \mathrm{~h}$ and $2-7 \mathrm{~h}$ after provision of feed were higher $(P<0.05)$ for group A than for group B (Table 2).

Rumen-fluid FOR $2-7 \mathrm{~h}$ after feed was offered were not different $(P>0.05)$ between animals given the hay and pellet diets, with both diets resulting in a higher $(P<0.05)$ FOR than the concentrate diet.

Mean reticulo-rumen volumes (litres, or litres $/ \mathrm{kg}$ body-weight) were higher $(P<0.05)$ in group B than in group A (Table 2). Diet had no influence $(P>0.05)$ on rumen volumes.

The passage rate-constants of the 1-2 mm Cr-mordanted particles were greater $(P<$ $0.05)$ for cattle fed on the concentrate diet compared with those in cattle given either hay or pellets (Table 2). Cr-mordanted PPR constants were not significantly influenced by cattle group type.

\section{Foam measurements}

Amount of foam produced from rumen fluid $3 \mathrm{~h}$ before feeding was not different $(P>0.05)$ between the animal groups (Table 3 ), however, the mean foam heights after provision of feed were higher $(P<0.05)$ in group B than in group A ( 150 and $240 \mathrm{~mm}$ at $2 \mathrm{~h}$ and 60 and $150 \mathrm{~mm}$ at $4 \mathrm{~h}$ respectively). The foam heights recorded 2 and $4 \mathrm{~h}$ after feeding for all diets were negatively correlated $(r-0.74$ and -0.85 respectively; $P<0.05)$ (Table 4$)$ with FOR of rumen fluid $0-2 \mathrm{~h}$ and $2-7 \mathrm{~h}$ after feed was offered for both groups of animals. FOR before feeding described only $6 \%$ of the variation in amount of foam produced $3 \mathrm{~h}$ before feeding.

The amount of foam produced was higher $(P<0.05)$ for the concentrate diet than for the hay and pellet diets $3 \mathrm{~h}$ before feeding (Table 3 ). No differences in foam heights were detected between diets at $4 \mathrm{~h}$ after feeding. Foam heights showed significant negative correlations $(r-0.89$ and -0.99 respectively; $P<0.05$ ) with rumen-fluid FOR for all cattle given hay 2 and $4 \mathrm{~h}$ after feeding (Table 4). However, for the pellet diet the correlation reached significance $(r-0.89 ; P<0.05)$ only at $2 \mathrm{~h}$ after feeding. For the concentrate diet, the correlation was significant $(r-0.83 ; P<0.05)$ only at $4 \mathrm{~h}$ after feeding (Table 4$)$. There was a lack of significance between the correlations of rumen-fluid FOR and amounts of foam produced from rumen contents $3 \mathrm{~h}$ before feeding in all diets.

Cattle in the different groups and cattle fed on different diets showed similar percentage decreases in foam heights $5 \mathrm{~min}$ after initial foam formation at both $3 \mathrm{~h}$ before and $4 \mathrm{~h}$ after feeding, therefore only measurements made $2 \mathrm{~h}$ after feeding are shown (Table 3 ). There were no $(P>0-05)$ differences in foam instability between the two groups. Differences between the hay and pellet diets also lacked significance, although both diets resulted in less- 
Table 1. Feed consumption patterns of bloat-resistant (group A) and bloat-susceptible (group $B$ ) cattle fed on chopped lucerne (Medicago sativa) hay (hay), lucerne pellets (pellets) and high-barley-grain (concentrate) diets

(Means with pooled standard errors)

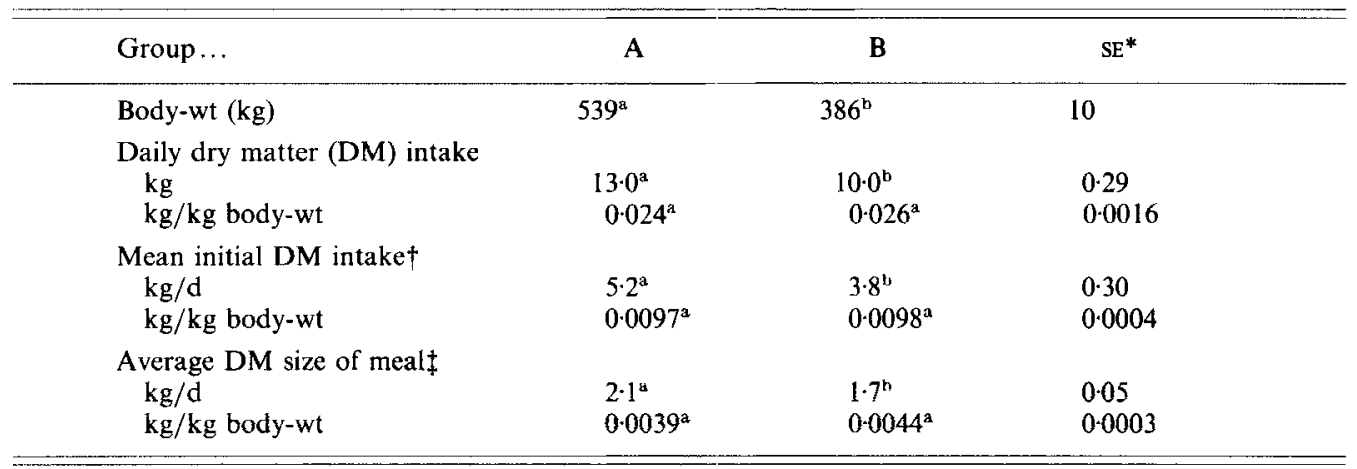

a, b Within horizontal rows, means with different superseript letters were significantly different $(P<0 \cdot 05)$.

* SE of cattle group means ( $n 9$, df 6 ).

$\uparrow$ Intake after provision of fresh feed until animals left feedbunk.

$\$$ Values obtained from total feed intake and number of visitations made to feed in an $8-12 \mathrm{~h}$ period.

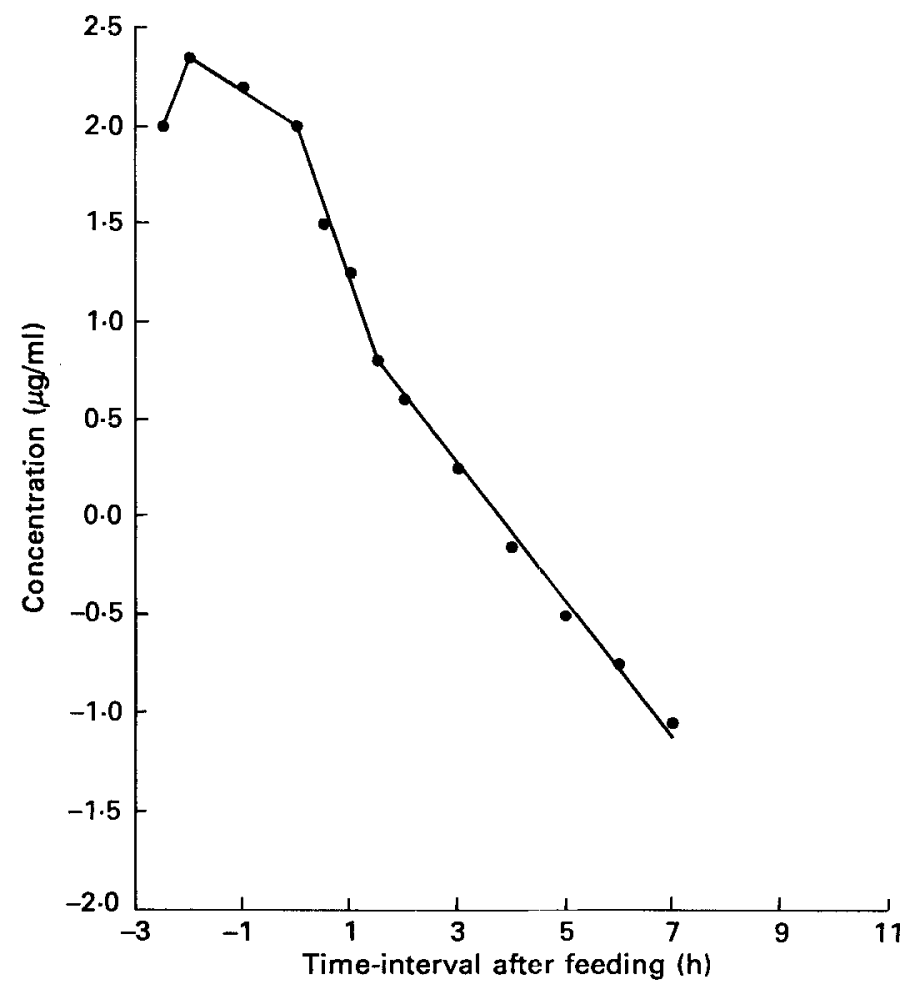

Fig. 1. Example of a multiple-component marker-concentration curve of CoEDTA in the rumen of cattle. Marker was given $3 \mathrm{~h}$ before feeding. 
Table 2. Rumen digesta kinetics in bloat-resistant (group A) and bloat-susceptible (group B) cattle fed on chopped lucerne (Medicago sativa) hay (hay), lucerne pellets (pellets) and highbarley-grain (concentrate) diets

(Means with pooled standard errors)

\begin{tabular}{|c|c|c|c|c|c|c|c|}
\hline & \multicolumn{3}{|c|}{ Group } & \multicolumn{4}{|c|}{ Diets } \\
\hline & A & B & $\mathrm{SE}^{*}$ & Hay & $\begin{array}{c}\text { Concen- } \\
\text { trate }\end{array}$ & Pellets & $\mathrm{SE}^{\dagger}$ \\
\hline $\begin{array}{l}\text { Rumen volume } \\
\text { Litres } \\
\mathrm{kg} / \mathrm{kg} \text { body-wt }\end{array}$ & $\begin{array}{l}87.9^{\mathrm{a}} \\
0.163^{\mathrm{a}}\end{array}$ & $\begin{array}{l}95 \cdot 6^{\mathrm{b}} \\
0.233^{\mathrm{b}}\end{array}$ & $\begin{array}{l}1 \cdot 20 \\
0.011\end{array}$ & $\begin{array}{l}97 \cdot 1^{\mathrm{a}} \\
0 \cdot 209^{\mathrm{a}}\end{array}$ & $\begin{array}{l}87 \cdot 8^{\mathrm{a}} \\
0 \cdot 189^{\mathrm{a}}\end{array}$ & $\begin{array}{l}90 \cdot 0^{\mathrm{a}} \\
0 \cdot 194^{\mathrm{a}}\end{array}$ & $\begin{array}{l}3 \cdot 1 \\
0 \cdot 01\end{array}$ \\
\hline $\begin{array}{l}\text { Fluid passage rate constan } \\
2 \cdot 5-0 \mathrm{~h} \text { before feeding } \\
0-2 \mathrm{~h} \text { after feed offered } \\
2-7 \mathrm{~h} \text { after feed offered }\end{array}$ & $\begin{array}{l}0 \cdot 077^{\mathrm{a}} \\
0 \cdot 205^{\mathrm{a}} \\
0 \cdot 16^{\mathrm{a}}\end{array}$ & $\begin{array}{l}0.049^{\mathrm{a}} \\
0.093^{\mathrm{b}} \\
0.086^{\mathrm{b}}\end{array}$ & $\begin{array}{l}0.009 \\
0.007 \\
0.005\end{array}$ & $\begin{array}{l}0 \cdot 08^{\mathrm{a}} \\
0 \cdot 173^{\mathrm{a}} \\
0 \cdot 143^{\mathrm{a}}\end{array}$ & $\begin{array}{l}0 \cdot 07^{\mathrm{a}} \\
0-13^{\mathrm{b}} \\
0 \cdot 093^{\mathrm{b}}\end{array}$ & $\begin{array}{l}0 \cdot 063^{\mathrm{a}} \\
0 \cdot 145^{\mathrm{b}} \\
0 \cdot 134^{\mathrm{a}}\end{array}$ & $\begin{array}{l}0.056 \\
0.004 \\
0.003\end{array}$ \\
\hline $\begin{array}{l}\text { Fluid outflow rate } \\
(1 / h) \ddagger\end{array}$ & $7 \cdot 4^{a}$ & $4 \cdot 5^{b}$ & 0.50 & $7 \cdot 9^{\mathrm{a}}$ & $6 \cdot 0^{a}$ & $5 \cdot 6^{a}$ & 0.54 \\
\hline $\begin{array}{l}\text { Passage rate of } 1-2 \mathrm{~mm} \\
\mathrm{Cr}-\mathrm{MP}(/ \mathrm{h})\end{array}$ & $0.067^{\mathrm{a}}$ & $0.050^{\mathrm{a}}$ & 0.012 & $0-047^{a}$ & $0.072^{\mathrm{b}}$ & $0.055^{\mathrm{a}}$ & 0.002 \\
\hline
\end{tabular}

a, b Within horizontal rows and comparisons, means with different superscript letters were significantly different $(P<0 \cdot 05)$.

Cr-MP, Cr-mordanted particles.

* SE of cattle group means $(n 9$, df 6$)$.

$\uparrow$ SE of diet means ( $n 6$, df 2 ).

Fluid outflow rate was estimated for the time period from 2.5 to $0 \mathrm{~h}$ before feeding.

Table 3. Foam stability and foam heights $(\mathrm{mm})$ produced in samples of rumen contents taken before and after feeding from bloat-resistant (group A) and bloat-susceptible (group B) cattle fed on chopped lucerne (Medicago sativa) hay (hay), lucerne pellets (pellets) and high-barleygrain (concentrate) diets

(Means with pooled standard errors)

\begin{tabular}{lcccc}
\hline \hline & & Foam heights $(\mathrm{mm})$ & \\
Time after feeding $(\mathrm{h}) \ldots$ & -3 & 2 & 4 & $\begin{array}{c}\text { Foam } \\
\text { instability }\end{array}$ \\
\cline { 2 - 5 } & & & & \\
Group & $79^{\mathrm{a}}$ & $150^{\mathrm{a}}$ & $69^{\mathrm{a}}$ & $43^{\mathrm{a}}$ \\
A & $82^{\mathrm{a}}$ & $240^{\mathrm{b}}$ & $150^{\mathrm{b}}$ & $40^{\mathrm{a}}$ \\
B & $9 \cdot 9$ & $12 \cdot 1$ & $11 \cdot 9$ & $1 \cdot 6$ \\
SE & & & & $54^{\mathrm{a}}$ \\
Diet & $32^{\mathrm{a}}$ & $148^{\mathrm{a}}$ & $76^{\mathrm{a}}$ & $22^{\mathrm{b}}$ \\
Hay & $122^{\mathrm{b}}$ & $236^{\mathrm{b}}$ & $135^{\mathrm{a}}$ & $50^{\mathrm{a}}$ \\
Concentrate & $87^{\mathrm{a}}$ & $194^{\mathrm{ab}}$ & $102^{\mathrm{a}}$ & $1 \cdot 11$ \\
Pellets & $2 \cdot 7$ & $7 \cdot 8$ & $16 \cdot 0$ & \\
SE & & &
\end{tabular}

a, b Within vertical columns and comparisons, means with different superscript letters were significantly different $(P<0.05)$.

* Values represent the difference between initial foam height after gassing for $2 \mathrm{~min}$ and the foam height $5 \mathrm{~min}$ after gassing, expressed as a percentage of initial foam height measured $2 \mathrm{~h}$ after feeding.

$+\mathrm{SE}$ of mean $(n 9, \mathrm{df} 6)$.

$\ddagger$ SE of mean $(n 6, \mathrm{df} 2)$. 
Table 4. Correlation coefficients ( $\mathrm{r}$ ), slopes and intercepts of linear regressions between foam heights $(\mathrm{mm})$ and rumen-fluid fractional outflow rates $(/ h)$ at various times after feeding

\begin{tabular}{|c|c|c|c|}
\hline \multirow[b]{2}{*}{ Diet $†$} & \multicolumn{3}{|c|}{ Time after feeding $(\mathrm{h}) \ldots$} \\
\hline & -3 & 2 & 4 \\
\hline \multicolumn{4}{|l|}{ All diets } \\
\hline Intercept & $8 \cdot 77$ & $27 \cdot 3$ & $18 \cdot 0$ \\
\hline Slope & $-0 \cdot 18$ & $-9 \cdot 63$ & -0.63 \\
\hline SEt & $0 \cdot 18$ & $0 \cdot 14$ & 0.096 \\
\hline$r$ & -0.24 & $-0.74^{*}$ & $-0.85^{*}$ \\
\hline \multicolumn{4}{|l|}{ Hay } \\
\hline Intercept & $12 \cdot 0$ & $39 \cdot 4$ & $20 \cdot 6$ \\
\hline Slope & -0.28 & -1.49 & -0.96 \\
\hline SEß & 0.15 & $0 \cdot 38$ & 0.06 \\
\hline$r$ & -0.70 & $-0.89^{*}$ & $-0.99^{*}$ \\
\hline \multicolumn{4}{|l|}{ Concentrate } \\
\hline Intercept & $6 \cdot 33$ & $8 \cdot 5$ & $17 \cdot 1$ \\
\hline Slope & -0.05 & $-0 \cdot 24$ & -0.55 \\
\hline $\mathrm{SE} \S$ & $0 \cdot 40$ & 0.85 & $0 \cdot 19$ \\
\hline$r$ & $-0 \cdot 30$ & $-0 \cdot 40$ & $-0.83^{*}$ \\
\hline \multicolumn{4}{|l|}{ Pellets } \\
\hline Intercept & 3.67 & 33.9 & 16.6 \\
\hline Slope & -0.31 & -1.00 & -0.50 \\
\hline $\mathrm{SE} \S$ & 0.83 & 0.25 & 0.26 \\
\hline$r$ & $-0 \cdot 40$ & $-0.89^{*}$ & -0.72 \\
\hline
\end{tabular}

* $P<0.05$.

$\dagger$ For details, see p. 388.

$\ddagger$ SE of slope $(n 18, \mathrm{df} 16)$.

$\S$ SE of slope $(n 6, \mathrm{df} 4)$.

stable foam $(P<0.05)$ than the concentrate diet. Rumen-fluid FOR during all the sampling phases described at most only $15 \%$ of the variation in foam instabilities.

\section{DISCUSSION}

The decision to use cattle with previous histories of bloating only 3 months after rumen cannulation and to compare these with normal cattle which had been cannulated for 2 years and were larger was made deliberately to try to ensure that differences between the two groups of animals would exist. Because the groups of cattle were dissimilar it is not possible to make firm conclusions concerning the causes of bloating in cattle of group B, but relations between the tendency of rumen contents to foam and the FOR of rumen fluid and particulate matter can be examined, and it would be expected that cattle with more foam in their reticulo-rumen contents would be more susceptible to bloat (Howarth et al. 1986).

The greater amount of foam produced by samples of rumen contents from cattle fed on the concentrate diet accords with reports of higher incidence of bloat in cattle when fed on combinations of lucerne hay and barley grain (Geissler \& Thomas, 1966; Howarth, 1975).

Since there was no significant difference in foam instability between groups A and B, clearance of foam produced during and after feeding for a particular diet would be expected 
to be dependent on rumen-fluid FOR for that diet. Thus, in cattle with a significantly higher rumen-fluid FOR during and after feeding, e.g. group A of the present study, the accumulation of microbial and plant by-products, and therefore bloat, may be prevented. On the other hand, a lower rumen-fluid FOR during and after feeding, such as in group B, may not be high enough to prevent such accumulations of stable foam and, therefore, bloat.

For the hay diet the FOR 0-2 and 2-7 $\mathrm{h}$ after feeding accounted for 79 and $98 \%$ of the variation in amount of foam produced. Corresponding values for the pellet diet were 79 and $51 \%$ respectively. Rumen-fluid FOR accounted for only 16 and $69 \%$ of the variation in amount of foam produced $0-2 \mathrm{~h}$ and $2-7 \mathrm{~h}$ after feeding for cattle on the concentrate diet. The low correlation between FOR and foam production for the $0-2 \mathrm{~h}$ post-feeding sample for cattle fed on this diet is difficult to explain. However, it could be due to animal variability and the small number of animals involved in the present study, or it could indicate that for concentrate diets the relation between FOR and foam production is more complex than that for hay diets. For example, viscosity of rumen fluid has been shown to be positively correlated with the incidence of bloat in animals fed on a high-grain diet (Meyer \& Bartley, 1971). Also cattle spend less time eating a grain-based diet than a hay diet and saliva production during eating is less (Bartley, 1973). Reductions in anti-foaming salivary mucins entering the rumen and increases in mucinolytic bacteria in rumen fluid have also been reported in cattle fed on concentrate diets (Bartley \& Yadava, 1961).

Across all diets the FOR $0-2 \mathrm{~h}$ and $2-7 \mathrm{~h}$ after provision of feed accounted for 55 and $72 \%$ of the variation respectively, in the amount of foam produced from rumen contents of cattle. This suggests that the relation between FOR and foam production holds under a variety of post-feeding situations.

Feeding caused a sharp decline in CoEDTA concentration (Fig. 1), a decline which could be related to the initial intake of the cattle after provision of fresh feed. Feeding causes declines in marker concentrations through expanded rumen volume or increased rate of passage, or both (Warner \& Stacy, 1968; Stokes et al. 1985).

The higher FOR for the hay diet $0-2 \mathrm{~h}$ after feeding could be attributed to increased mastication and salivation with the chopped hay compared with the concentrate and pellet diets. However, when the cattle were no longer actively eating (2-7 h after provision of feed) the FOR was not significantly different between the animals given the chopped and pelleted hay diets.

The slower FOR of rumen fluid for group B at the various sampling phases are in agreement with the results of Majak et al. (1986b) who, during our analysis of the results from this study, reported first-order rate-constants of 0.043 and $0.092 / \mathrm{h}$ for bloatsusceptible and bloat-resistant cattle respectively. However, results in our study indicate that, although overall FOR may be important in explaining bloat differences, it may be more important to consider the relations between the various components which contribute to the overall FOR and foam production. Thus, an overall slower FOR for group B could be attributed to significantly slower rates of passage of CoEDTA during and after feeding and the concomitant higher foam production, but not to a slower FOR before feeding. It is during and after feeding that most animals normally bloat (Howarth, 1975).

Group B had significantly larger reticulo-rumen volumes than group A. Cockrem et al. (1983) reported significant differences in rumen volumes between high-susceptible and lowsusceptible cattle, and indicated that a greater volume of rumen fluid could be associated with a high susceptibility to bloat.

The mean fractional passage rates of the $1-2 \mathrm{~mm} \mathrm{Cr}$-mordanted particles, though higher in group A, were not significantly different from those of group B. Particles which could be responsible for frothiness by causing an increase in the viscosity of the lamellae fluid, 
thus preventing drainage of the fluid, as suggested by Majak et al. (1986a), could be smaller than $1 \mathrm{~mm}$ and thus would move with the liquid phase.

In conclusion, in the present experiment the study of animal factors involved in bloat susceptibility in cattle have been expanded to include the relation between FOR of fluids before feeding, during feeding and after active feeding and the amounts of foam produced from rumen contents during these times. Cattle with a history of being bloat-susceptible (group B) had greater foam productions from rumen contents and slower liquid FOR after feeding than cattle which were not bloat-susceptible (group A), whereas before feeding there was no significant difference in FOR and in amount of foam produced. The low FOR in group B could cause foaming agents to accumulate and account for increased tendency for animals to bloat.

This study was part of a research programme supported by the 'Farming for the Future' programme of the Agricultural Research Council of Alberta. E. K.O. is a recipient of a Commonwealth Scholarship while on study leave from the University of Ghana, Legon, Ghana.

\section{REFERENCES}

Association of Official Analytical Chemists (1975). Official Methods of Analysis, 12th ed. Washington, DC: Association of Official Analytical Chemists.

Bartley, E. E. (1973). Cattle bloat - cause, prevention and treatment of legume and feedlot types. In Beef Cattle Science Handbook, pp. 108-118 [M. E. Ensminger, editor]. Clovis, California: Agriservices Foundation.

Bartley, E. E. \& Yadava, I. S. (1961). Feedlot bloat prevention with proloxalene. Journal of Animal Science 26, 913 Abstr.

Cockrem, F. R. M., McIntosh, J. T. \& McLaren, R. (1983). Selection for and against susceptibility to bloat in dairy cows - a review. Proceedings of the New Zealand Society of Animal Production 43, 101-106.

Geissler, B. R. \& Thomas, O. O. (1966). Proloxalene as a bloat preventative for wintering calves on barley and alfalfa rations. Journal of Animal Science 25, 589 Abstr.

Goering, H. K. \& Van Soest, P. J. (1970). Forage Fiber Analyses. US Department of Agriculture, Agricultural Handbook no. 379. Washington, DC: US Department of Agriculture.

Howarth, R. E. (1975). A review of bloat in cattle. Canadian Veterinary Journal 16, 281-294.

Howarth, R. E., Cheng, K.-J., Majak, W. \& Costerton, J. W. (1986). Ruminant bloat. In Control of Digestion and Metabolism in Ruminants, pp. 516-527 [L. P. Milligan, W. L. Grovum and A. Dobson, editors]. Englewood Cliffs: Prentice Hall.

Majak, W., Hall, J. W. \& Howarth, R. E. (1986a). The distribution of chlorophyll in rumen contents and the onset of bloat in cattle. Canadian Journal of Animal Science 66, 97-102.

Majak, W., Hall, J. W, Rode, L. M. \& Kalnin, C. M. (1986b). Rumen clearance rates in relation to the occurrence of alfalfa bloat in cattle. 1. Passage of water-soluble markers. Journal of Dairy Science 69, 1560-1567.

Majak, W., Howarth, R. E., Cheng, K.-J. \& Hall, J. W. (1983). Rumen conditions that predispose cattle to pasture bloat. Journal of Dairy Science 66, 1683-1688.

Mendel, V. E. \& Boda, J. M. (1961). Physiological studies of the rumen with emphasis on the animal factors associated with bloat. Journal of Dairy Science 44, 1881-1898.

Meyer, R. M. \& Bartley, E. E. (1971). Bloat in cattle. XV. The relation of viscosity and cell-free polysaccharide content of rumen fluid to feedlot bloat. Journal of Animal Science 33, 1018-1021.

Pressey, R., Synhorst, S. H., Janet, B., Allen, R. S. \& Jacobson, N. L. (1963). Foaming properties of alfalfa and their relationship to bloat. Journal of Animal Science 22, 970-978.

Steel, R. G. D. \& Torrie, J. H. (1980). Principles and Procedures of Statistics. New York: McGraw-Hill Book Co.

Stokes, M. R., Bull, L. S. \& Halteman, W. A. (1985). Rumen liquid dilution rate in dairy cows fed once daily: Effects of diet and sodium bicarbonate supplementation. Journal of Dairy Science 68, 1171-1180.

Uden, P., Colucci, P. E. \& Van Soest, P. J. (1980). Investigation of chromium, cerium and cobalt as markers in digesta. Rate of passage studies. Journal of the Science of Food and Agriculture 31, 625-632.

Warner, A. C. I. \& Stacy, B. D. (1968). The fate of water in the rumen. 2. Water balances throughout the feeding cycle in sheep. British Journal of Nutrition 22, 389-410. 